\section{Dancing hookworm in the small bowel detected by capsule endoscopy: a synthesized video}
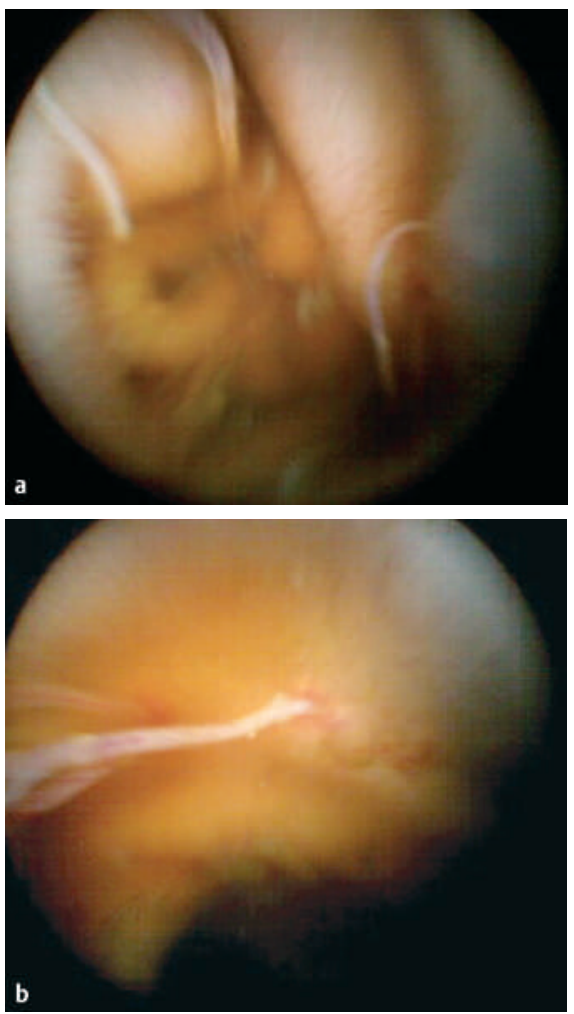

Figure 1 a, b Capsule endoscopy showed multiple worms sticking to the small-bowel mucosa.
A 38-year-old Chinese woman presented to our hospital, complaining of a 3-month history of black stool passage and dizziness. Laboratory test results included hemoglobin, $40 \mathrm{~g} / \mathrm{L}$ (normal: $120-160 \mathrm{~g} / \mathrm{L}$ ); red blood cell count, $2.08 \times 10^{12} / \mathrm{L}(4.0-$ $\left.5.5 \times 10^{12} / \mathrm{L}\right)$; white cell count, $15.48 \times 10^{9} /$ L $\left(4.0-10.0 \times 10^{9} / \mathrm{L}\right)$; eosinophils, $30.1 \%$ $(0.5 \%-5 \%)$; platelet count, $424 \times 10^{9} / \mathrm{L}$ $\left(100-300 \times 10^{9} / \mathrm{L}\right)$. Stool examination was positive for occult blood while negative for ova and parasites. Both upper gastrointestinal endoscopy and colonoscopy showed negative results. Other biochemistry examination results, including electrolytes, and liver and renal functions were within normal limits. The patient underwent transfusion of four units of packed red blood cells. A capsule endoscopy (OMOM; Chongqing Jinshan Science \& Technology Inc., China) performed to evaluate the patient further for occult gastrointestinal tract bleeding showed multiple worms throughout the small bowel (Figure 1). Interestingly, the sequence of figures from 02:31:26 (h:min:s) to $02: 33: 02$ showed a hookworm sticking to and "dancing" on the small-bowel mucosa. A total of 75 frames chosen from the sequence were turned into a video (Video 1) (Adobe Premiere 6.5; Adobe Systems Incorporated, California, USA). The patient refused enteroscopy and further examinations because of poor economic circumstances. Follow-up showed good recovery after treatment with oral albendazole.
Endoscopy_UCTN_Code_CCL_1AC_2AG

\section{Z.-S. Li, Z. Liao, P. Ye, R.-P. Wu}

Department of Gastroenterology, Digestive Endoscopy Center, Changhai Hospital, Second Military Medical University, Shanghai, China.

\section{Corresponding author}

\section{Z.-S. Li, MD}

Department of Gastroenterology Digestive Endoscopy Center

Changhai Hospital

Second Military Medical University 174 Changhai Road

Shanghai 200433

China

Fax: $\quad$ +86-21-55620081

Email: zhaoshenli@hotmail.com

\section{Video 1}

A video synthesized from the frame sequence obtained between 02:31:26 (h:min:s) and 02:33:02 showed a hookworm sticking to and "dancing" on the small-bowel mucosa. 